\title{
Energy drinks mixed with alcohol: misconceptions, myths, and facts
}

This article was published in the following Dove Press journal:

International Journal of General Medicine

I March 2012

Number of times this article has been viewed

\section{Joris C Verster' \\ Christoph Aufricht ${ }^{2}$ \\ Chris Alford ${ }^{3}$}

'Utrecht University, Utrecht Institute for Pharmaceutical Sciences, Division of Pharmacology, Utrecht, The Netherlands; ${ }^{2}$ Medical University of Vienna, Department of Pediatrics and Adolescent Medicine, Währinger Gürtel, Wien, Austria; ${ }^{3}$ University of the West of England, Psychology Department, Faculty of Health and Life Sciences, Frenchay Campus, Coldharbour Lane, Bristol, UK
Correspondence: Joris C Verster Utrecht University, Utrecht Institute for Pharmaceutical Sciences, Division of Pharmacology, Universiteitsweg 99, 3584 CG Utrecht, The Netherlands Tel +3I 0302536909

Email j.c.verster@uu.nl
Background: Whilst energy drinks improve performance and feelings of alertness, recent articles suggest that energy drink consumption combined with alcohol may reduce perception of alcohol intoxication, or lead to increased alcohol or drug use. This review discusses the available scientific evidence on the effects of mixing energy drinks with alcohol.

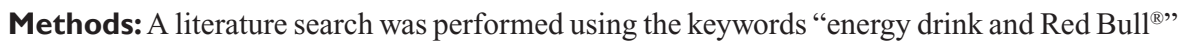
and consulting Medline/Pubmed, PsycINFO, and Embase.

Results: There is little evidence that energy drinks antagonize the behavioral effects of alcohol, and there is no consistent evidence that energy drinks alter the perceived level of intoxication of people who mix energy drinks with alcohol. No clinically relevant cardiovascular or other adverse effects have been reported for healthy subjects combining energy drinks with alcohol, although there are no long-term investigations currently available. Finally, whilst several surveys have shown associations, there is no direct evidence that coadministration of energy drinks increases alcohol consumption, or initiates drug and alcohol dependence or abuse.

Conclusion: Although some reports suggest that energy drinks lead to reduced awareness of intoxication and increased alcohol consumption, a review of the available literature shows that these views are not supported by direct or reliable scientific evidence. A personality with higher levels of risk-taking behavior may be the primary reason for increased alcohol and drug abuse per se. The coconsumption of energy drinks being one of the many expressions of that type of lifestyle and personality.

Keywords: energy drink and Red Bull ${ }^{\circledR}$, Red Bull ${ }^{\circledR}$, alcohol, intoxication, caffeine, masking

\section{Introduction}

Although energy drinks comprise only $1 \%$ of the total soft drink market, these products are becoming increasingly popular. ${ }^{1}$ The market leader, Red Bull ${ }^{\circledR}$ Energy Drink is available in over 160 countries and, although some local sales restrictions may apply, energy drinks are not banned in any country. The most important functional ingredient of energy drinks is caffeine. Table 1 lists some of the well known energy drink brands, and their caffeine content.

It is evident from Table 1 that popular energy drinks such as Red Bull $(250 \mathrm{~mL}, 8.4 \mathrm{oz})$ contain a similar amount of caffeine (ie, $80 \mathrm{mg}$ ) to that present in one regular cup of coffee $(240 \mathrm{~mL}, 8 \mathrm{oz}){ }^{2,3}$ However, less popular brands may have a higher caffeine content. Caffeine does not have adverse effects for the general population of healthy adults if they limit caffeine intake to $400 \mathrm{mg}$ per day. ${ }^{4}$ Various experimental studies have examined the behavioral effects of energy drinks when consumed alone. Most studies have shown that energy drink consumption can significantly improve cognitive 
Table I Caffeine content of some well known energy drinks ${ }^{2,3}$

\begin{tabular}{llll}
\hline & $\begin{array}{l}\text { Bottle/can } \\
\mathbf{m L}(\mathbf{o z})\end{array}$ & $\begin{array}{l}\text { Caffeine } \mathbf{~ m g / l 0 0 ~} \mathbf{~ m L} \\
(\mathbf{m g} / \mathbf{o z})\end{array}$ & $\begin{array}{l}\text { Total caffeine } \\
\mathbf{~ m g}(\text { range) }\end{array}$ \\
\hline Red bull & $250(8.4)$ & $32(9.6)$ & 80 \\
Monster & $473(16)$ & $34(10)$ & 160 \\
Rockstar & $473(16)$ & $34(10)$ & 160 \\
Full throttle & $473(16)$ & $30(9)$ & 144 \\
No fear & $473(16)$ & $37(10.9)$ & 174 \\
Amp & $250(8.4)$ & $30(8.9)$ & 75 \\
SoBe & $250(8.4)$ & $32(9.5)$ & 79 \\
Tab energy & $311(10.5)$ & $31(9.1)$ & 95 \\
Cola & $355(12)$ & $11(3.3)$ & $40(30-60)$ \\
Coffee & $237(8)$ & $36(10.6)$ & $85(65-120)$ \\
Tea & $237(8)$ & $17(5)$ & $40(20-90)$ \\
\hline
\end{tabular}

and psychomotor functioning ${ }^{5-10}$ and driving ability, ${ }^{10-12}$ preexercise consumption can significantly improve endurance and physical performance, ${ }^{7,13-15}$ and whilst some studies have reported small changes in heart rate or blood pressure, no clinically relevant adverse cardiovascular effects have been reported after normal use of energy drinks in healthy volunteers, ${ }^{7,16-21}$ although there is currently a lack of longterm data.

Health regulatory authorities across the world have concluded that energy drinks are safe to consume, although some authorities have expressed concerns about the potential health risks associated with mixing alcohol and caffeine. It should also be noted that there are anecdotal and case reports of acute adverse effects, including fatalities, in individuals consuming energy drinks combined with alcohol, but no confirmation of any causal relationship between the reported effects and the consumption of energy drinks. ${ }^{22}$

Research and media attention has recently been drawn to alcohol mixed with energy drinks (AmED). In this context, it has been suggested that AmED consumption may reduce the perception of alcohol intoxication or that coconsumption may lead to increased alcohol consumption. This paper aims to review and put into perspective the current scientific evidence on the combined use of energy drinks and alcohol.

\section{Methods}

A literature search was performed (updated December 1, 2011) using the keywords "energy drink" and "Red Bull", consulting Medline/Pubmed, PsycINFO, and Embase for clinical trials and surveys examining the effects of energy drinks consumed together with alcohol. Cross-references were checked for additional research papers. This literature search yielded 23 research articles that were included in this review.

\section{Results}

Most people consume energy drinks only occasionally (eg, less than $6 \%$ of college students consume energy drinks daily). ${ }^{23}$ Surveys among students reveal that they consume energy drinks to counteract sleepiness, to enhance energy and concentration, ${ }^{24}$ or because they simply like it. ${ }^{25}$ Reasons given for consuming energy drinks combined with alcohol include "during partying", ${ }^{24}$ to celebrate, ${ }^{26}$ because they like the taste, ${ }^{26}$ to hide the flavor of alcohol, ${ }^{27}$ or to get drunk. ${ }^{26}$ However, only $2 \%$ of all students (and 15\% of those who combined alcohol with energy drinks) indicated they did so in an attempt to be able to drink more and not feel as drunk. ${ }^{27}$

Surveys among students have found that $6 \%-44 \%$ report consumption of AmED. ${ }^{24-32}$ Price et al interviewed 72 regular consumers of energy drinks about their past week and lifetime energy drink and alcohol intake, applying the timeline follow-back approach. ${ }^{33}$ Thirteen percent of past-week alcohol consumption sessions involved the co-use of energy drinks. Analysis of survey data revealed that students who consume AmED were significantly more often young white males. ${ }^{27,31,34}$ Taken together, these surveys suggest that a relative minority of students occasionally consume AmED.

\section{Do energy drinks antagonize} alcohol-induced performance impairment? Seven studies examined the possible antagonizing effects of energy drinks on alcohol-induced performance impairment, including both recovery from physical exercise and cognitive testing. ${ }^{16,35-40}$ The results of these studies are summarized in Table 2 .

A significant limitation of two of these studies ${ }^{36,37}$ is that alcohol was not tested alone, so it cannot be determined if the effects caused by AmED are actually the same as when administering alcohol alone. Ferreira et al failed to find significant differences on a variety of physical performance and recovery parameters. ${ }^{16}$ The statistical analysis reported by Marczinski et al, based on significant changes from baseline, found that some aspects of cognitive performance were poorer for alcohol alone compared with the energy drink, placebo, or AmED groups, but not for all tests. ${ }^{38}$ In a second study, Marczinski et al did not find any significant difference between impairment on information processing and motor coordination tasks between AmED and alcohol only. ${ }^{39}$ Ferreira et al also failed to show differences between alcohol and AmED, ${ }^{35}$ whilst Alford et al showed improvement with AmED in one test, but not others, compared with alcohol. ${ }^{40}$ Therefore, there is mixed evidence that energy drink consumption antagonizes some performance effects 


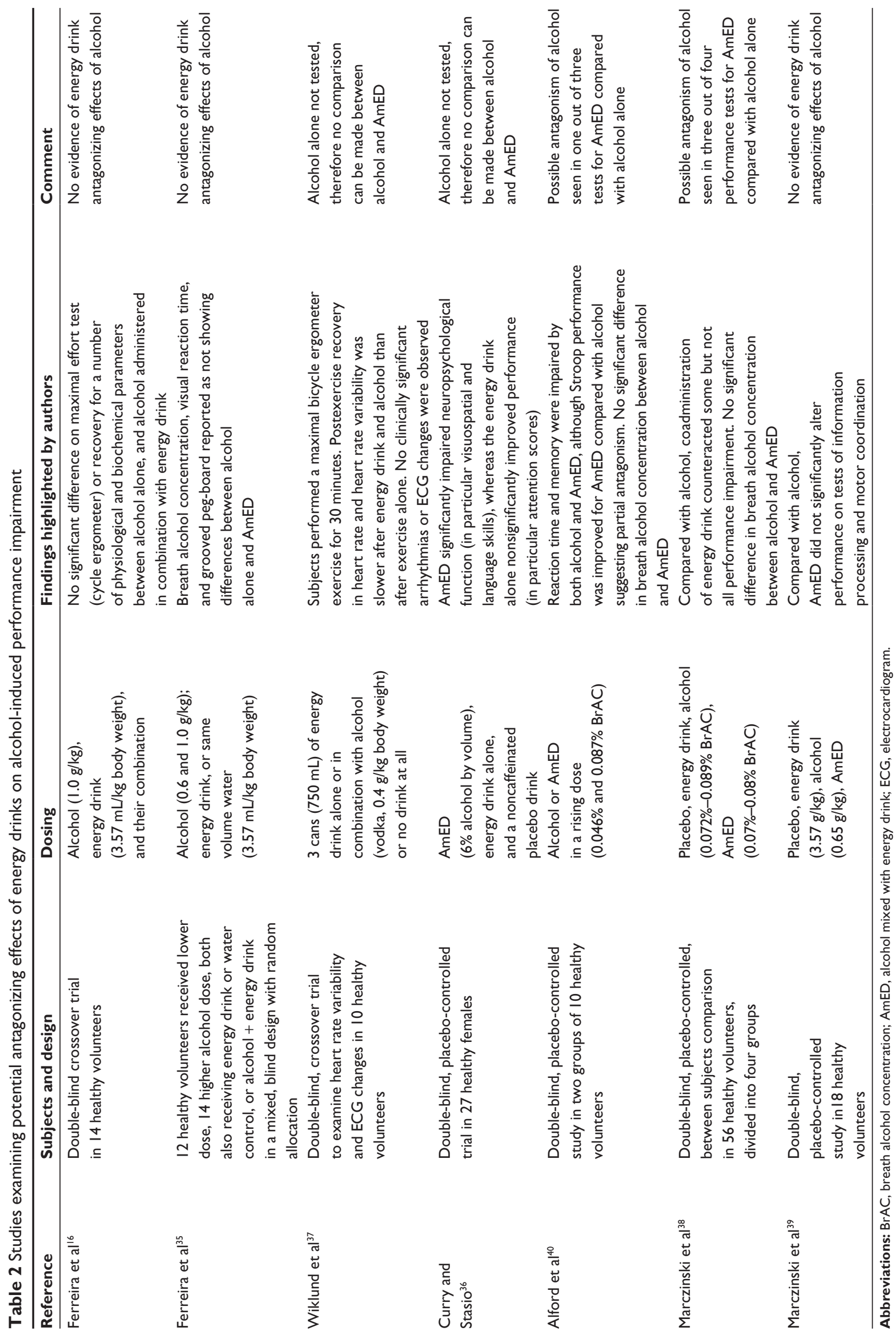


caused by alcohol intoxication but not others. This suggests no consistent antagonism of alcohol-induced impairment by coconsumption of energy drinks. A recent double-blind, placebo-controlled study by Howland et al did not observe any significant differences on simulated driving, sustained attention, or reaction time between caffeinated and noncaffeinated beer (383 mg caffeine, peak breath alcohol concentration [BrAC] of $0.12 \%$ ), suggesting no consistent antagonism of alcohol-induced impairment by coconsumption of caffeine. ${ }^{41}$

\section{Do energy drinks change the drinker's perception of intoxication?}

It has been claimed that people consume energy drinks because they presume it will counteract the impairing effects of alcohol. For example, O'Brien et al reported this for $15 \%$ of students who consumed AmED. ${ }^{27}$ Few experimental studies actually examined the perception of intoxication after consuming AmED. One of the most cited studies in this context was performed by Ferreira et al, who evaluated breath alcohol concentration $(0.04 \%-0.1 \% \mathrm{BrAC})$, psychomotor functioning, and subjective intoxication after administration of an energy drink, alcohol (vodka, 0.6 or $1.0 \mathrm{~g} / \mathrm{kg}$ ), or AmED. ${ }^{35}$ Twenty-six subjects participated in this randomized, controlled trial. Coadministration of energy drink did not affect breath alcohol concentration. Symptoms during intoxication were scored using the Bond and Lader 13 -item somatic symptoms scale, ${ }^{42,43}$ extended with five additional items, giving 18 items in all. The paper revealed that alcohol and AmED similarly impaired psychomotor performance. The results section reports that AmED reduced the perception of headache, dry mouth, and impairment of motor coordination compared with alcohol alone. However, the appropriateness of using these symptoms as a measure of intoxication should be questioned, especially because most other symptoms, of which several are related to feelings of intoxication (eg, dizziness, speech, tiredness, vision, walking, wellbeing), did not show a significant reduction for AmED compared with alcohol alone. Consequently, the interpretation of these results as showing a reduction in perceived intoxication after AmED compared with alcohol alone cannot be taken as consistent and reliable on the basis of this single study.

Alford et al found participants felt significantly impaired after alcohol (0.05\%-0.09\% BrAC) and significantly impaired by the higher compared with lower alcohol dose (4/5 scales), but no overall difference between alcohol alone and energy drink combined with alcohol. ${ }^{40}$
Marczinski et al reported that alcohol alone (0.07-0.09 BrAC) significantly increased ratings of feeling the drink, liking the drink, impairment, and level of intoxication, whereas it reduced the rating of ability to drive. ${ }^{38}$ AmED showed no significant difference for these ratings. The abstract of this article implies that self-reported stimulation was increased for AmED compared with alcohol alone, and that this might contribute to a higher risk scenario. However, their data showed that subjective stimulation was significantly increased from baseline for both the alcohol and AmED groups. Unfortunately, in this paper, no direct statistical comparisons were made between the AmED and alcohol group. In a second study, Marczinski et al reported that consumption of AmED reduced mental fatigue and increased feelings of stimulation, when compared with consuming alcohol alone. ${ }^{39}$ No significant difference between AmED and alcohol alone was reported on subjective intoxication or ability to drive. Taken together, the results from these studies do not show a change in perceived intoxication on the majority of subjective scales, including intoxication and ability to drive, when alcohol is mixed with energy drink. Higher levels of alcohol have been compared with alcohol and caffeine in combination, though not using energy drinks. Howland et al investigated higher doses of alcohol comparing the effects of caffeinated beer versus noncaffeinated beer, and nonalcoholic beer in 127 nondependent, heavy episodic drinkers, aged $21-30$ years. ${ }^{41}$ When a peak BrAC of $0.12 \%$ was achieved, there was no significant difference in estimated BrAC between caffeinated and noncaffeinated beer, indicating that caffeine (a total dose of $383 \mathrm{mg}$ on average) did not mask the alcohol intoxication effects, and thereby supporting the majority of findings observed with energy drinks.

\section{Do energy drinks enhance alcohol consumption?}

Given the stimulant effects of caffeine-containing energy drinks, it has been suggested that when consumed together with alcohol, energy drinks would increase alcohol ingestion. Although no experimental data are available, several surveys examined the coconsumption of energy drinks and alcohol. ${ }^{27-34,44-48}$ The design and results of these studies, which are nearly all from the US, are summarized in Table 3. In addition to the conclusions drawn by the respective authors, Table 3 also includes our interpretation of the data in the comment column.

Arria et al conducted a 3-year longitudinal study aiming to examine illicit drug use patterns among college students (the 2003 College Life Study). ${ }^{49}$ Annually, they interviewed 


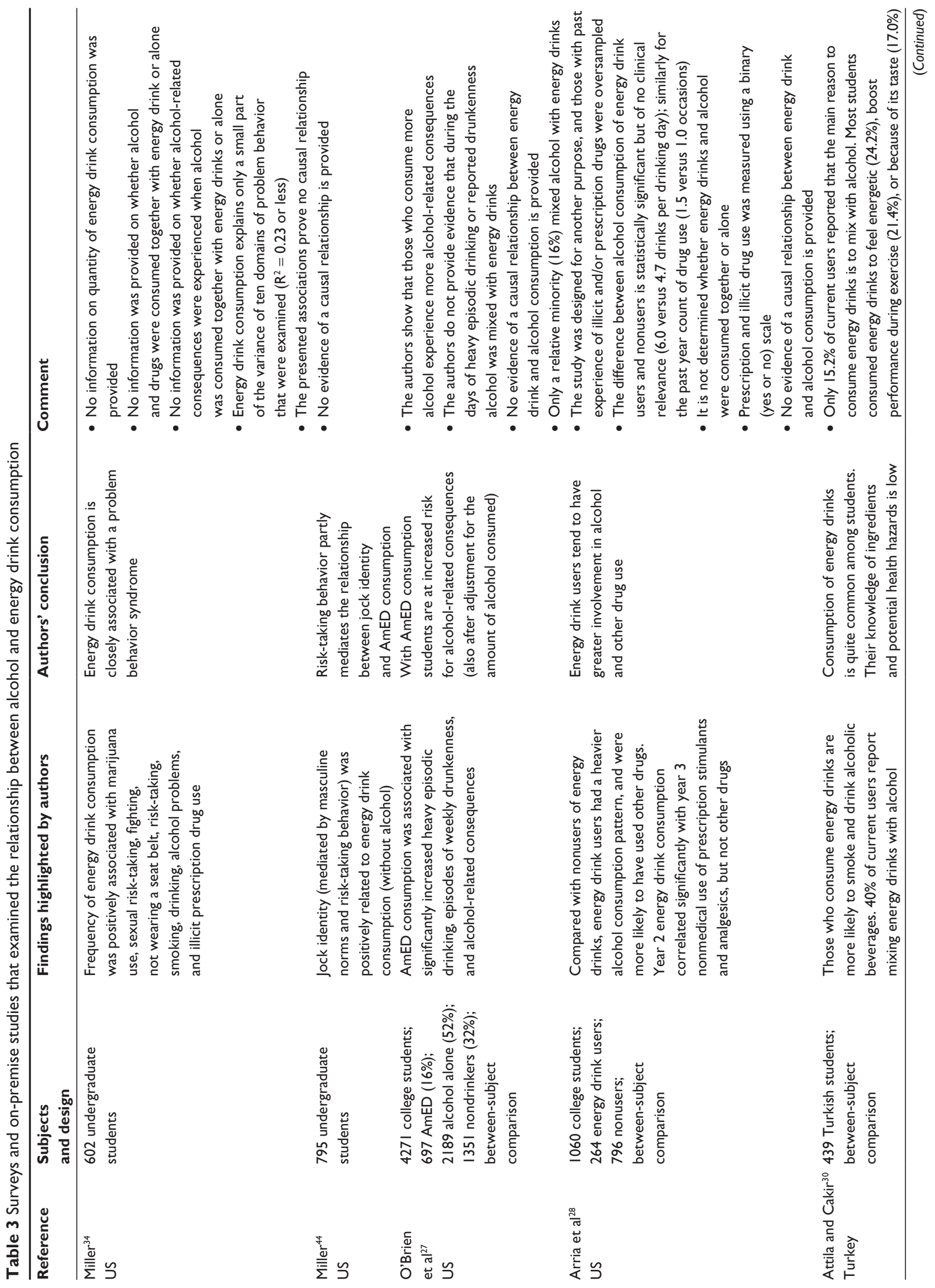




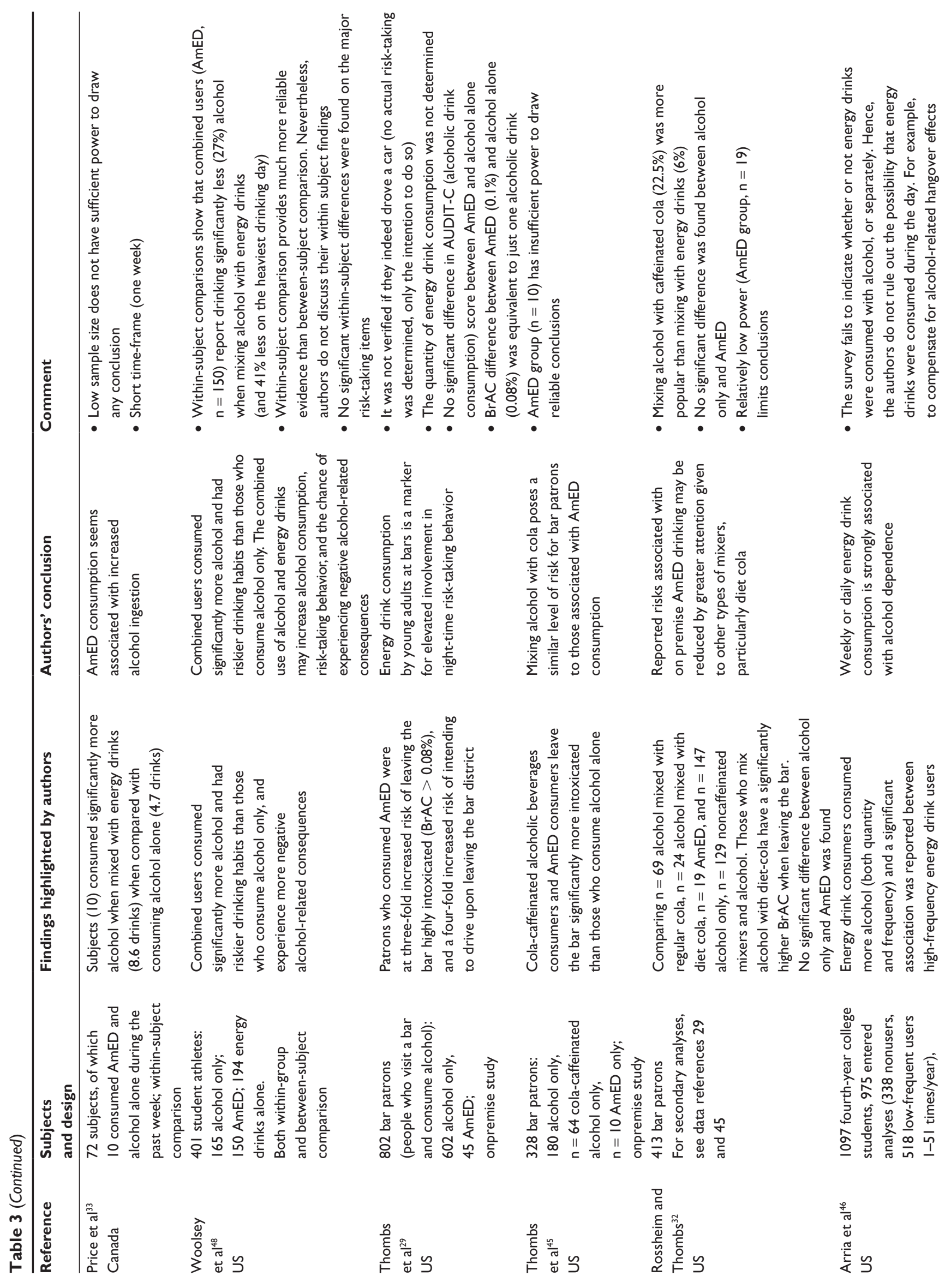



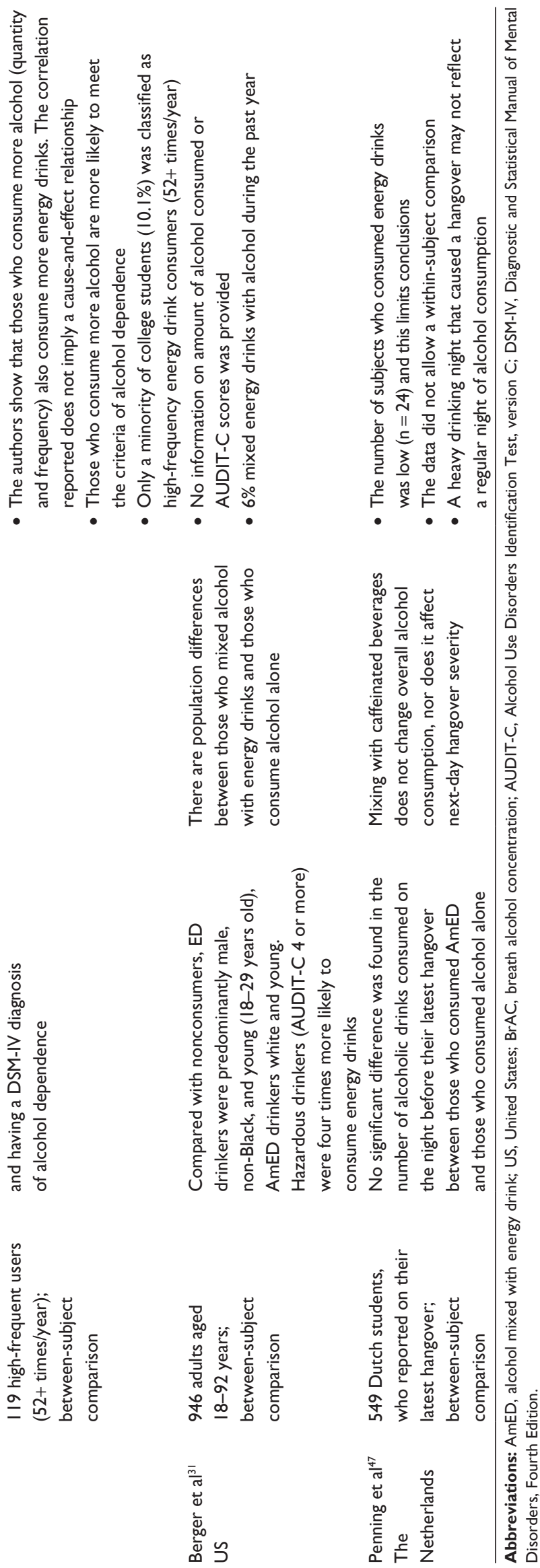

1063 college students. To ensure a sufficient number of eligible subjects, those with past experience of illicit and/or prescription drugs were oversampled. An exploratory analysis of the data was performed comparing those who consume energy drinks and those who do not. ${ }^{28}$ Since the study was not set up for this purpose, only two questions about energy drink consumption were asked. These questions were "What types of caffeinated products do you consume?" and "Estimate the typical, minimum, and maximum number of caffeinated drinks you consume during a typical week". Based on the first question, subjects were classified as energy drink users $(n=264)$ and those who do not consume energy drinks $(n=796)$. Energy drink consumers reported significantly more alcohol intake (both quantity and frequency). Illicit drug use was not significantly higher in energy drink consumers, nor was the use of medicinal drugs, except for prescription stimulants and analgesics. Subjects also completed the short form of the Zuckerman-Kuhlman Personality Questionnaire. Energy drink consumers scored significantly higher on the subscale of impulsive, sensation-seeking behavior.

Unfortunately, the authors did not gather any specific data on whether energy drinks were mixed with alcohol or not. Also, prescription and illicit drug use was only measured using a binary (yes or no) scale. Recently, Arria et al published data from the fourth yearly interview of students participating in the 2003 College Life Study ${ }^{46}$ In this interview, students estimated the types of energy drinks and the number of days and usual quantity of energy drinks they consumed during the previous 12 months. The statistical analysis showed an association between energy drink and alcohol consumption, and reported that those who "frequently" consume energy drinks ( $\geq 52$ days per year, ie, $\geq 1$ per week; representing $10.1 \%$ of the sample) significantly more often met the Diagnostic and Statistical Manual of Mental Disorders, Fourth Edition (DSM-IV) criteria for alcohol dependence. However, the survey also failed to indicate whether or not energy drinks were consumed together with alcohol, or separately. In fact, in both studies, the authors do not rule out the possibility that energy drinks were consumed separately during the day, or the day after to compensate for alcohol-related hangover effects. ${ }^{28,46}$

A survey among 4271 college students by O'Brien et al showed that consumption of AmED was associated with increased heavy episodic drinking (6.4 days versus 3.4 days in the past 30 days) and weekly drunkenness (1.4 days/week versus 0.73 days/week), and experiencing negative alcoholrelated consequences significantly more often. ${ }^{27}$ Again, this study also does not provide any evidence for a causal 
relationship, but does support the association that when people drink more alcohol they may also mix some of their alcohol with energy drinks.

Price et al interviewed 10 regular energy drink users about their past week and lifetime energy drink and alcohol use. ${ }^{33}$ These 10 subjects consumed significantly more alcohol on the occasion that they also consumed energy drinks (8.4 versus 4.7 alcoholic consumptions, respectively). The authors acknowledge the small sample size and recommend additional research, but nevertheless conclude that using energy drinks is associated with increased alcohol consumption.

Thombs et al examined energy drink and alcohol use in a naturalistic setting, ie, college bars, between $10.00 \mathrm{pm}$ and $03.00 \mathrm{am} .^{29}$ In a bar district, 802 subjects were interviewed about their alcohol use and energy drink consumption and performed a breath analysis test to estimate BrAC. Subjects also completed the shortened Alcohol Use Disorders Identification Test (AUDIT-C), a measure of quantity/ frequency of consumption, and were asked how likely it was that they would drive home by car at the end of their night out. Significant differences were observed between those who consumed alcohol only $(n=602)$ and those who mixed energy drinks with alcohol $(n=46)$; the differences included mean $\mathrm{BrAC}$ (0.08\% versus 0.11\%), alcohol consumed $(95.3 \mathrm{~g}$ versus $152.2 \mathrm{~g}$ ), and total hours of drinking (2.9 hours versus 3.9 hours) for these two groups, respectively. AUDIT-C scores did not significantly differ between the groups.

Logistic regression analysis revealed that those who mixed alcohol and energy drinks were 3.32 times more likely to leave the bar intoxicated ( $\mathrm{BrAC} \geq 0.08 \%$ ) and had a 4.26 times increased risk of intending to drive a car after leaving. The authors concluded that the latter suggests perception of alcohol-induced impairment is reduced when coconsumed with energy drinks. An alternative explanation may be that the groups already differed at baseline in alcohol consumption and risk perception. In a second study by Thombs et al, only 10 people reported consuming AmED. ${ }^{45}$ Therefore, the conclusions drawn based on the data from this small study should be interpreted with caution. Rossheim and Thombs then combined the data from both onpremise studies. ${ }^{32}$ Based on the combined data, they concluded that energy drink consumption was not associated with an increased risk of being intoxicated.

Miller conducted a survey among 602 undergraduate students that indicated energy drink consumption was associated with problem behaviors, particularly among white students. ${ }^{34}$ Frequency of energy drink consumption was positively associated with marijuana use, smoking, drinking, alcohol problems, illicit drug use, and risk-taking behavior. In a second survey among 795 undergraduate students, Miller confirmed that levels of conformity to masculine norms, risk-taking behavior, and sport-related ("jock") identity significantly predicted the frequency of energy drink consumption. ${ }^{44}$

Berger et al reported ethnic and other differences between those who consume alcohol alone compared with energy drink users, or those who consume AmED. ${ }^{31}$ These differences were noted by the authors, who then suggest subgroup targeting for health information. However, they fail to point out that the observed increase in "hazardous drinking" for the AmED group may be accounted for by intergroup differences alone (eg, age, ethnicity), rather than to AmED consumption.

A finding from several surveys has been that AmED consumption was associated with increased alcohol consumption..$^{27,28,46}$ These surveys show that research comparing different groups (eg, those who combine alcohol with energy drinks and those who do not) is always difficult to interpret, and can yield potentially biased results because baseline and other characteristics of the groups have not been controlled for and may differ significantly. This potential bias can be prevented by conducting research using a withinsubject design, ie, comparing drinking occasions in the same subjects with and without energy drink consumption and using an appropriate sample size. This design was applied in a recent survey by Woolsey et al among athletes. ${ }^{48}$ When comparing drinking habits of those who drink alcohol only $(n=165)$ and those who mixed alcohol with energy drinks $(n=150)$ these researchers showed that those who consumed AmED drank alcohol significantly more often, drank more alcohol on single occasions, reported more heavy drinking episodes, and had consumed twice the amount of alcohol during the past year when compared with the group that never mixed alcohol with energy drinks.

However, when looking at the group that combined energy drinks with alcohol, it was shown that on occasions when they did mix alcohol and energy drinks they consumed significantly less alcohol (6.28 drinks) when compared with occasions when they consumed alcohol without energy drinks (8.60 drinks) a reduction of $27 \%$. Also, when reporting on the greatest number of alcoholic drinks consumed on a single occasion during the past year, the combined group reported significantly less alcohol consumption (10.83 drinks) when combining alcohol with energy drinks compared with a session of alcohol without energy drinks (18.23 drinks), ie, a reduction of $41 \%$. Also, no significant within subject 
differences were found on the major risk-taking items "taking risks", "being brave and daring", and "being likely to fight", whereas the statistically significant differences found for “acting aggressively" (2.46 versus 2.76$)$ and "driving a motor vehicle" (1.57 versus 1.75) for alcohol versus AmED, respectively, reflect only small numerical differences and therefore have no clinical relevance.

Unfortunately, the authors concluded their article with a discussion of the potential dangers of energy drinks and a call for action to protect the public, and disregarded their own findings showing that alcohol consumption within subjects was substantially reduced when mixing alcohol with energy drinks.

Interestingly, recent onpremise studies reveal that the single focus on energy drinks as a mixer for alcohol may be unjustified and misplaced, because other caffeinated mixers such as cola beverages are more popular than energy drinks. ${ }^{29,32,45}$ They showed that mixing alcohol with caffeinated cola $(22.5 \%)$ was much more popular than mixing with energy drinks (6\%). Breathalyzer assessment on leaving the bar revealed that $\mathrm{BrAC}$ levels were similar in those who consumed alcohol mixed with cola (BrAC $0.108 \%$ ) or consumed AmED (BrAC 0.106\%), and somewhat higher than found in those who consumed alcohol only (BrAC 0.091\%). A recent survey confirmed these findings among Dutch students, when reporting on their latest night out that caused a hangover. ${ }^{47} \mathrm{No}$ difference in total alcohol consumption was found between those who consumed alcohol alone or AmED, whereas those who mixed alcohol with cola beverages consumed significantly more alcohol.

In conclusion, the specific nature of the relationship between energy drink consumption and alcohol consumption, if any, cannot be established from these surveys. The fact that two things occur together (ie, the presented correlations in the surveys between energy drink and alcohol consumption) does not imply that one causes the other. ${ }^{50}$ More direct and reliable within-subject comparisons comparing occasions of alcohol intake both with and without energy drink consumption, such as performed by Woolsey et $\mathrm{al}^{48}$ are necessary to establish if there is an actual difference, and to what extent energy drinks influence alcohol consumption, or not. ${ }^{50}$

\section{Discussion}

Excessive and irresponsible consumption of alcoholic drinks has adverse effects on human health and behavior, but it should be clear that this is due to the alcohol, and not the mixer. When presenting their data, several authors fail to acknowledge that correlations between energy drink and alcohol consumption do not provide any cause-and-effect relationship. ${ }^{50,51}$ Instead, they describe the "high" risk of combined use of energy drinks and alcohol" as "a growing problem"3 or "a new hazard for adolescents", ${ }^{53}$ without providing supportive scientific evidence, or they simply copy the conclusions of other authors without having a closer look at the methodology of the surveys and the way the data were analyzed and presented. ${ }^{54}$ This way of presenting and interpreting scientific data may raise unsubstantiated concerns among consumers and parents about the use of energy drinks (alone or in combination with alcohol) and may actually trigger unjustified regulations in the absence of appropriate data. Some recent reviews have copied the conclusions of these authors, summarizing the data and its interpretation as offered by the authors that conducted these studies, draw unjustified conclusions, or present recommendations for legislation that are not supported by the available scientific data. ${ }^{53-55}$

However, other authors have commented on the current energy drink debate and disputed the conclusions drawn in these reviews. ${ }^{50,51,56}$ Other criticism focuses on the methodology and setup of previous studies, some of which were underpowered or were not specifically designed to examine the association between energy drink consumption and alcohol consumption. ${ }^{49}$ Given the limitations of these studies (summarized in Tables 2 and 3), Skeen and Glenn $^{56}$ concluded that there is an "imaginary link between alcoholism and energy drinks", and Verster and Alford ${ }^{50}$ concluded that the concerns about energy drinks are not justified by the currently available scientific data. But most importantly, when judging articles on energy drinks mixed with alcohol, it should be kept in mind that correlation does not mean causation. ${ }^{51}$

In fact, there are many alternative explanations. Several surveys compared groups of subjects who do and do not combine alcohol with energy drinks. As some surveys on energy drink consumption suggested, it is possible that the groups of subjects that were compared already differed at baseline regarding the level of risk-taking behavior and other personality traits. ${ }^{28,34,44,46,48}$ This may explain the observed differences in alcohol and drug use between the groups. People who are high risk-takers are more likely to exhibit life-style behaviors characterized by disinhibition and loss of moderation. These behaviors include increased frequency and amount of alcohol consumption, caffeine consumption, smoking, and recreational drug use, as well as gambling and engagement in risk-taking behavior. ${ }^{57,58}$ Being a high risk-taker may then be the cause of increased alcohol consumption. 
A significant association between levels of risk-taking behavior (measured as sensation-seeking, impulsivity, and related traits) has been reported for alcohol and drug use, , $^{59,60}$ as well as energy drinks. ${ }^{28,34,44,46,48}$ These surveys link the consumption of energy drinks with a risk-taking lifestyle that is already characterized by higher levels of alcohol consumption. In other words, a personality with higher levels of risk-taking behavior may be the primary reason for increased alcohol and drug abuse. The coconsumption of energy drinks is just one of the many expressions of such a lifestyle and personality.

Given that energy drink companies often market their products by relating them to extreme sports and adventurous activities, it is understandable that individuals who are attracted to energy drinks more often have a higher risktaking profile.

Seven main conclusions can be drawn from the available scientific literature:

- There are currently insufficient properly controlled studies to draw any firm conclusions regarding the effects of energy drinks mixed with alcohol

- A relative minority of students occasionally mix energy drinks with alcohol, and there is no evidence that energy drinks are consumed more than other caffeinated drinks (eg, colas) combined with alcohol

- There is some evidence that energy drinks may antagonize some, but not all, aspects of alcohol-induced performance impairment

- There is no consistent evidence that energy drinks alter the perceived level of intoxication of people who mix energy drinks with alcohol

- Whilst there are associations between the levels of alcohol and energy drink consumption, there is no evidence that coconsumption of energy drinks causes increased alcohol consumption

- There is no direct evidence that coconsumption of alcohol and energy drinks initiates drug and alcohol dependence or abuse

- A personality with higher levels of risk-taking behavior may be the primary reason for increased alcohol and drug abuse. The coconsumption of energy drinks may be one of the many expressions of their lifestyle and personality type.

These conclusions are drawn from the limited evidence available at this time. Hence, more and better research is needed. Properly controlled clinical studies, surveys, and prospective studies are required before definite conclusions can be drawn. In order to define the effects of an energy drink, such clinical studies must include sessions of administration of both energy drink or placebo drink (ie, an energy drink without the active ingredients) as well as alcohol alone, and whenever possible applying a within-subject design. Such designs are more complex but essential if the focus is on the effects of energy drinks on alcohol consumption. Until these data are available, interventions with the primary goal of reducing alcohol consumption and related problems should focus on the availability and consumption of alcohol per se.

\section{Disclosure}

Over the last 3 years, Joris Verster has received research funding from Takeda Pharmaceuticals, Deenox, and Red Bull $\mathrm{GmbH}$, and done consultancy work for Takeda, Sepracor, Sanofi Aventis, Deenox, Red Bull GmbH, CBD, Trimbos Institute, and Transcept. Chris Alford has received funding from the UK Ministry of Defence, Red Bull GmbH, and Sanofi-Aventis. Christoph Aufricht has received research funding from the Austrian Science Fund, the European Community, Fresenius Medical Care, Baxter Healthcare, and Zytoprotec.

\section{References}

1. Canadean Wisdom Database: Available at: http://www.canadean.com/ Products/Wisdom_Database.aspx. Accessed August 15, 2011.

2. International Food Information Council Foundation. IFIC Review: Caffeine and health: clarifying the controversies, 1998. Available at: http:// www.foodinsight.org/Resources/Detail.aspx?topic=IFIC_Review_ Caffeine_and_Health_Clarifying_the_Controversies_. Accessed January 21, 2012.

3. Reissig CJ, Strain EC, Griffiths RR. Caffeinated energy drinks a growing problem. Drug Alcohol Depend. 2009;99:1-10.

4. Health Canada. Caffeine updated. It's your health. Available at: http://www.hc-sc.gc.ca/fn-an/securit/addit/caf/food-caf-aliments-eng. php. Accessed August 18, 2011.

5. Mucignat-Caretta C. Changes in female cognitive performance after energetic drink consumption: a preliminary study. Prog Neuropsychopharmacol Biol Psychiatry. 1998;22:1035-1042.

6. Seidl R, Peyrl A, Nicham R, Hauser E. A taurine and caffeine-containing drink stimulates cognitive performance and well-being. Amino Acids. 2000;13:635-642.

7. Alford C, Cox H, Wescott R. The effects of Red Bull Energy Drink on human performance and mood. Amino Acids. 2001;21:139-150.

8. Horne JA, Reyner LA. Beneficial effects of an "energy drink" given to sleepy drivers. Amino Acids. 2001;20:83-89.

9. Smit HJ, Grady ML, Finnegan YE, Hughes S-AC, Cotton JR, Rogers PJ. Role of familiarity on effects of caffeine- and glucose-containing soft drinks. Physiol Behav. 2006;87:287-297.

10. Gershon P, Shinar D, Ronen A. Evaluation of experience-based fatigue countermeasures. Accid Anal Prev. 2009;41:969-975.

11. Reyner LA, Horne JA. Efficacy of a 'functional energy drink' in counteracting driver sleepiness. Physiol Behav. 2002;75:331-335.

12. Mets MAJ, Ketser S, Blom C, et al. Effects of Red Bull ${ }^{\circledR}$ energy drink on prolonged highway driving. Psychopharmacology (Berl). 2011;214:737-745.

13. Geiss K-R, Jester I, Falke W, Hamm M, Waag K-L. The effect of a taurine-containing drink on performance in 10 endurance-athletes. Amino Acids. 1994;7:45-56. 
14. Ivy JL, Kammer L, Ding Z, et al. Improved cycling time-trial performance after ingestion of a caffeine energy drink. Int J Sport Nutr Exerc Metab. 2009;19:61-78.

15. Walsh AL, Gonzalez AM, Ratamess NA, Kang J, Hoffman JR. Improved time to exhaustion following ingestion of the energy drink Amino Impact ${ }^{\mathrm{TM}}$. J Int Soc Sports Nutr. 2010;7:14.

16. Ferreira SE, de Mello MT, Rossi MV, de Souza-Formigoni MLO. Does an energy drink modify the effects of alcohol in a maximal effort test? Alcohol Clin Exp Res. 2004;28:1408-1412.

17. Rashti SL, Ratamess NA, Kang J, Faigenbaum AD, Chilakos A, Hoffman JR. Thermogenic effect of meltdown RTD energy drink in young healthy women: a double blind, cross-over design study. Lipids Health Dis. 2009;8:57.

18. Steinke L, Lanfear DE, Dhanapal V, Kalus JS. Effect of "energy drink" consumption on hemodynamic and electrocardiographic parameters in healthy young adults. Ann Pharmacother. 2009;43:596-602.

19. Lockwood CM, Moon JR, Smith AE, et al. Low-calorie energy drink improves physiological response to exercise in previously sedentary men: a placebo-controlled efficacy and safety study. J Strength Cond Res. 2010;24:2227-2238.

20. Ragsdale FR, Gronli TD, Batool N, et al. Effect of Red Bull energy drink on cardiovascular and renal functioning. Amino Acids. 2010;38:1193-1200.

21. Worthley MI, Prabhu A, de Scisco P, Schultz C, Sanders P, Willoughby SR. Detrimental effects of energy drink consumption on platelet and endothelial function. Am J Med. 2010;123:184-187.

22. European Food Safety Authority. Scientific Opinion of the Panel on Food Additives and Nutrient Sources added to Food on a request from the commission on the use of taurine and D-glucurono- $\gamma$-lactone as constituents of the so-called "energy" drinks. Available at: http://www. efsa.europa.eu/en/efsajournal/doc/ans_ej935_Taurine $\% 20$ and $\% 20$ D-glucuronolactone_op_en,1.pdf?ssbinary=true. Accessed January 22, 2012.

23. West DS, Nursac Z, Quimby D, et al. Self-reported sugarsweetened beverage intake among college students. Obesity. 2006; 14:1825-1831.

24. Malinauskas BM, Aeby VG, Overton RF, Carpenter-Aeby T, BarberHeidal K. A survey of energy drink consumption patterns among college students. Nutr J. 2007;6:35.

25. Oteri A, Salvo F, Caputi AP, Calapai G. Intake of energy drinks in association with alcoholic beverages in a cohort of students of the School of Medicine of the University of Messina. Alcohol Clin Exp Res. 2007;31:1677-1680.

26. Marczinski CA. Alcohol mixed with energy drinks: consumption patterns and motivations for use in US college students. Int J Environ Res Public Health. 2011;8:3232-3245.

27. O'Brien MC, McCoy TP, Rhodes SD, Wagoner A, Wolfson M. Caffeinated cocktails: energy drink consumption, high-risk drinking, and alcohol-related consequences among college students. Acad Emerg Med. 2008;15:453-460.

28. Arria AM, Caldeira KM, Kasperski SJ, et al. Increased alcohol consumption, nonmedical prescription drug use, and illicit drug use are associated with energy drink consumption among college students. J Addict Med. 2010;4:74-80.

29. Thombs D, Rossheim M, Barnett T, Weiler R, Moorhouse M, Coleman B. Is there a misplaced focus on AmED? Associations between caffeine mixers and bar patron intoxication. Drug Alcohol Depend. 2010;116:31-36.

30. Attila S, Çakir B. Energy-drink consumption in college students and associate factors. Nutrition. 2011;27:316-322.

31. Berger LK, Fendrich M, Chen HY, Arria AM, Cisler RA. Sociodemographic correlates of energy drink consumption with and without alcohol: results of a community survey. Addict Behav. 2011;36: 516-519.

32. Rossheim ME, Thombs DL. Artificial sweeteners, caffeine, and alcohol intoxication in bar patrons. Alcohol Clin Exp Res. 2011;35: 1891-1896.
33. Price SR, Hilchey CA, Darredeau C, Fulton HG, Barrett SP. Energy drink co-administration is associated with increased reported alcohol ingestion. Drug Alcohol Rev. 2010;29:331-333.

34. Miller KE. Energy drinks, race, and problem behaviors among college students. J Adolesc Health. 2008;43:490-497.

35. Ferreira SE, de Mello MT, Pompéia S, de Souza-Formigoni MLO. Effects of energy drink ingestion on alcohol intoxication. Alcohol Clin Exp Res. 2006;30:598-605.

36. Curry K, Stasio MJ. The effects of energy drinks alone and in combination with alcohol on neuropsychological functioning. Hum Psychopharmacol. 2009;24:473-481.

37. Wiklund U, Karlsson M, Öström M, Messner T. Influence of energy drinks and alcohol on post-exercise heart rate recovery and heart rate variability. Clin Physiol Funct Imaging. 2009;29: 74-80.

38. Marczinski CA, Fillmore MT, Bardgett ME, Howard MA. Effects of energy drinks mixed with alcohol on behavioral control: risks for college students consuming trendy cocktails. Alcohol Clin Exp Res. 2011;35:1282-1292.

39. Marczinski CA, Fillmore MT, Henges AL, Ramsey MA, Young CR. Effects of energy drinks mixed with alcohol on information processing, motor coordination and subjective reports of intoxication. Exp Clin Psychopharmacol. 2011. [Epub ahead of print.]

40. Alford C, König J, Aufricht C, Verster JC. Proceedings of the 2010 Energy Drinks Symposium. Available at: http://benthamscience. com/open/toneuroppj/articles/V004/1TONEUROPPJ.pdf. Accessed January 22, 2012.

41. Howland J, Rohsenow DJ, Arnedt JT, et al. The acute effects of caffeinated versus non-caffeinated alcoholic beverage on driving performance and attention/reaction time. Addiction. 2010;106:335-341.

42. Bond AJ, Lader MH. Residual effects of hypnotics. Psychopharmacologia. 1972;25:117-132.

43. Greenwood MH, Lader MH, Kantameneni BD, Curzon G. The acute effects of oral (-)-tryptophan in human subjects. Br J Clin Pharmacol. $1975 ; 2: 165-172$.

44. Miller KE. Wired: energy drinks, jock identity, masculine norms, and risk taking. J Am Coll Health. 2008;56:481-489.

45. Thombs D, O'Mara R, Tsukamoto M, et al. Event level analysis of energy drink consumption and alcohol intoxication in bar patrons. Addict Behav. 2010;35:325-330.

46. Arria AM, Caldeira KM, Kasperski SJ, Vincent KB, Griffiths RR, O'Grady KE. Energy drink consumption and increased risk for alcohol dependence. Alcohol Clin Exp Res. 2011;35:1-11.

47. Penning R, de Haan L, Verster JC. Caffeinated drinks, alcohol consumption, and hangover severity. The Open Neuropsychopharmacol J. 2011;4:36-39.

48. Woolsey C, Waigandt A, Beck NC. Athletes and energy drinks: reported risk-taking and consequences from the combined use of alcohol and energy drinks. J Appl Sport Psychol. 2010;22:65-71.

49. Arria AM, Caldeira KM, O'Grady KE, et al. Drug exposure opportunities and use patterns among college students: results from a longitudinal prospective cohort study. Subst Abus. 2008;29:19-38.

50. Verster JC, Alford C. Unjustified concerns about energy drinks. Curr Drug Abuse Rev. 2011;4:1-3.

51. Siegel S. The Four-Loko effect. Perspect Psychol Sci. 2011;6(4): 357-362.

52. Arria AM, O'Brien MC. The "high" risk of energy drinks. JAMA. 2011; 305:600-601.

53. Pennington N, Johnson M, Delaney E, Blankenship MB. Energy drinks: a new health hazard for adolescents. J Sch Nurs. 2010;26: 352-359.

54. Higgins JP, Tuttle TD, Higgins CL. Energy beverages: content and safety. Mayo Clin Proc. 2010;85:1033-1041.

55. Pennay A, Lubman DI, Miller P. Combining energy drinks with alcohol. A recipe for trouble? Aust Fam Phys. 2011;40:104-107.

56. Skeen MP, Glenn L. Imaginary link between alcoholism and energy drinks. Alcohol Clin Exp Res. 2011;35:1375-1376. 
57. De Wit H. Impulsivity as a determinant and consequence of drug use: A review of underlying processes. Addict Biol. 2009;14:22-31.

58. Ohannessian CM, Hesselbrock VM. A finer examination of the role that negative affect plays in the relationship between paternal alcoholism and the onset of alcohol and marijuana use. J Stud Alcohol Drugs. 2009; 70:400-408.
59. De Haan L, Kuerten Y, Kuipers E, van Laar MW, Olivier B, Verster JC. The RT-18: a new screening tool to assess young adult risk taking behavior. Int J Gen Med. 2011;4:575-584.

60. Hosier SG, Cox WM. Personality and motivational correlates of alcohol consumption and alcohol-related problems among excessive drinking university students. Addict Behav. 2011;36:87-94.

\section{Publish your work in this journal}

The International Journal of General Medicine is an international, peer-reviewed open-access journal that focuses on general and internal medicine, pathogenesis, epidemiology, diagnosis, monitoring and treatment protocols. The journal is characterized by the rapid reporting of reviews, original research and clinical studies across all disease areas.
A key focus is the elucidation of disease processes and management protocols resulting in improved outcomes for the patient. The manuscript management system is completely online and includes a very quick and fair peer-review system. Visit http://www.dovepress.com/ testimonials.php to read real quotes from published authors.

Submit your manuscript here: http://www.dovepress.com/international-journal-of-general-medicine-journal 